\title{
University governance reforms: potential problems of more autonomy?
}

\author{
Tom Christensen
}

Published online: 30 December 2010

(C) The Author(s) 2010. This article is published with open access at Springerlink.com

\begin{abstract}
University governance reforms are very much a reflection of the broader New Public Management reforms that are focusing on increasing efficiency in public organizations. The article deals with how university reform ideas of a generic nature, emphasizing that universities should be treated and reformed like any other public organizations, are important and reflected in specific reform measures. The special empirical focus is on that universities through reforms are changing their formal affiliation to superior ministries in a more autonomous direction, implicating more autonomy in financial, management and decision-making matters. One the other hand, universities are also through reforms more exposed to more report, scrutiny and control systems, financial incentive systems, pressure to get resources from other sources than the government, cut-back management, etc. So a main question in the analysis is whether universities, as traditionally having quite a lot of real autonomy, through the reforms in fact are getting less autonomy, not more, like the reforms entrepreneurs often are promising. The analysis is based on a transformational approach from organization theory, representing a combination of structural, cultural and environmental factors of explanation for reforms processes and their effects. Empirically the article is based on the author's own empirical studies of university reform and reviews of comparative studies.
\end{abstract}

Keywords University governance - University reform - Control and autonomy - NPM · Transformative approach

\section{Introduction}

Public-sector reforms have been dominated over the last 20-30 years by two rather different trends. First, New Public Management (NPM) reforms were introduced in Australia and New Zealand in the early 1980s, subsequently spreading to other Anglo-American countries and then more widely around the world (Pollitt and Bouckaert 2004). NPM has

T. Christensen $(\bowtie)$

Department of Political Science, University of Oslo, P.O.Box 1097, Blindern, 0317 Oslo, Norway

e-mail: tom.christensen@stv.uio.no 
been built on the notion that there were three major problems in the public sectorefficiency, participation and legitimacy (Boston et al. 1996). The recipe for dealing with these questions was a mixed bag of reform elements based on a combination of new institutional economic theory and management theory and encompassing a structural reorganization of the public sector vertically (devolution) and horizontally (role purification), a greater focus on markets, competitive tendering and privatization and more emphasis on service provision and consumer-orientation (Christensen and Lægreid 2001a). NPM has been pushed through by governments in many countries, but the depth of the reforms - and hence the extent of change in practice - has varied quite a lot in line with differences in structural constraints, cultural traditions and environmental pressure (Christensen and Lægreid 2001b; Wright 1994).

The second main reform trend emerging in the late 1990s, which also originated in Australia and New Zealand and spread around the world, could be labeled post-NPM (Christensen et al. 2007). The post-NPM recipe for treating the ailments of NPM and other challenges has been to increase central control and capacity, partly through vertical integration, as well as to intensify cross-sectoral collaboration and coordination, or a combination of the two. The slogan has been to bring the system that NPM fragmented back together again, finding a Third Way, as in the UK, or furthering a whole-of-government approach, as it is called in Australia (Gregory 2003; Halligan 2006, 2007; Richards and Smith 2006). NPM did not disappear when post-NPM came along, but is still relatively strong. It has, however, been somewhat modified and been combined with post-NPM in a multi-layered system.

Reforms of university governance are in some ways likely to reflect the more general reform trends in the political-administrative system and society. However, since the higher education sector has its own very particular organizational and cultural traditions, shaped by the requirements of very specialized professional knowledge and academic freedom, there are also reasons to believe that general reforms are not very compatible with these and therefore difficult to implement in this sector.

The first research question posed in this article is how can we understand university governance and reforms? In other words, what kind of explanatory approach or analytical perspectives might be fruitful for understanding the dynamics, content and effects of university reform processes? Our approach is a transformational one, stressing that the leeway of political and administrative leaders in reform processes is defined by a complex context consisting of a combination of structural-instrumental, cultural-institutional and environmental factors (Christensen and Lægreid 2001a). Second, what are some of the main trends in university governance around the world? What are some of their main ideas and principles and what are some of the more specific reform measures used? Here we will concentrate on reforms of the affiliation form of universities and some major changes in how they are financed. ${ }^{1}$ Third, using a transformative approach, how can we analyze and understand the university reform trends-in particular the balance of central control and institutional autonomy? Our main thesis, based on this review, is that universities going through modern reforms experience more formal autonomy, but less real autonomy, because this new formal autonomy is having many strings attached, both structural and financial. Fourth, based on the transformational approach, a possible design for studying our main thesis of decreasing real autonomy will be outlined, implying discussing the theory, method and empirical implications.

1 There are a lot of other reform measures that are connected to these questions, like reforms in internal steering and management systems, but that is not discussed here (see Paradeise et al. 2009c: 228-230). 


\section{Perspectives on university reform}

The first perspective in a transformative approach to the study of public-sector organizations and reform is a structural-instrumental one (Christensen and Lægreid 2001a; Egeberg 2003; March and Olsen 1983). According to such a perspective, the structural design of public organizations is important for fulfilling collective public goals, and reorganizations will reflect changing goals. Hence, formal structures are considered to be instrumental in channeling the thoughts and actions of decision-makers in certain directions (Gulick 1937; Simon 1957). There are two crucial preconditions for using organizational design as an instrument in public organizations. One is that the actors must score relatively high on rational calculation or organizational thinking, another that they may be able to control the reform processes (Dahl and Lindblom 1953).

Two central structural concepts could be used to describe and analyze changes in the structural design of university systems. One is the type and extent of vertical structural specialization, that could either be inter- or intra-organizational (Egeberg 2003), meaning for example that subordinate units, like universities, can have different degrees and type of autonomy from the ministry in charge (inter-organizational). The other dimension is the horizontal specialization, that could also be inter- or intra-organizational, meaning to what extent and how units, roles or tasks/functions on the same level is specialized. Closely connected to spcialization is 'coordination through organization', as labeled by Gulick (1937), meaning that a formal organization, like a public one, could be coordinated vertically or horizontally, either in an inter- or intra-organizational way. Combining the two dimensions of specialization and coordination respectively, produce at the one extreme a very integrated political-administrative system, like 'old public administration' or features of post-NPM, while the other extreme is a very fragmented and specialized system, like the one recommended by NPM (Christensen and Lægreid 2001).

To discuss the main thesis outlined, a distinction could be made between formal autonomy and real autonomy. Formal autonomy could be judged more generally as whether the university reforms have implied increasing formal leeway for universities, decided by central authorities and reflected in changing laws. Alternatively, one can define the concept and say that it has different dimensions, i.e. universities may have different degrees of autonomy related to formal affiliation, to management systems, to financial systems, to standardization of research and teaching activities, etc. This means that formal autonomy is multi-dimensional and potentially hybrid, meaning that the different dimensions may imply variety in centralization/decentralization or control/autonomy.

Even though what is actually happening concerning decision-making processes and activities in universities will always be constrained by formal frames, one can also expects a gap between ideals and reality, leading to a concept of real or actual autonomy. This is quite parallel to a basic reasoning in instrumental organization theory (Simon 1957). One can make a distinction between formal structure and actual decision-making behavior inside that structure (Egeberg 2003). Like formal autonomy, actual autonomy is also multidimensional, both constrained by the structural frames of the different dimensions of formal autonomy, but also influenced by cultural and environmental factors.

This structural-instrumental perspective comes in two versions, one hierarchical and one negotiational (March and Olsen 1983). According to the hierarchical version, reform processes would be dominated by a closed group of top leaders, political or administrative/ institutional, that are scoring high both on control and unambiguous organizational thinking, i.e. they know why and how to reform and tightly control the process. A negotiational version start from the notion of heterogeneity in systems, institutions, interests, 
norms and values. Reform processes are more like a tug-of-war between different actors, both inside the leadership and among several groups with different interests. Reform decisions and implementation could be reached by majority, consensus or sequential attention to goals and interests (Cyert and March 1963). Reform process negotiations may, compared to a firm hierarchical steering of such process, be obstructive in bringing less clear reform measures and take more time, but often enhance the legitimacy of the reforms (Mosher 1967).

Such a perspective on university reforms focuses primarily on how and to what extent formal organizational factors are consciously designed, like how the relationship between superior ministries and universities is organized (affiliation form) and what the measures are for changing it, including different ways of steering various functions and tasks, but also financial/incentive and scrutiny systems. To help us describing and analyzing such systems, we can use the structural dimensions outlined above.

A cultural-institutional perspective on public organizations and reforms stresses that administrative-cultural traditions are important (Selznick 1957). Most public organizations develop institutional features (consisting of informal norms and values) over time through a process of institutionalization, which is characterized by adaptation to internal and external pressure (Boin and Christensen 2008). This process produces specific institutional features or what might be called a cultural profile and soul. Path-dependency means that the cultural roots that a public organization develops in its early years will heavily influence it during its later trajectory and development (Krasner 1988). The notion of cultural compatibility is important for understanding how reforms are handled in public organizations. A reform that is rather compatible with the basic cultural norms and values in an organization would be implemented rather easily, while a reform that is confrontational would be more likely to be bounced back, modified or only partly implemented.

Using such a perspective to study university governance and reforms means to focus on culture instead of formal structure. This may involve looking at the main ideas and principles of university reform to see what kind of underlying norms and values they represent, and how compatible these are with cultural traditions. It may also involve examining whether university reforms are aimed at changing a university's culture. A third way is to focus on particular reform elements to see whether they might have a differentiating effect on the major cultural norms and values in the universities. This may also imply that university culture is not one homogeneous set of norms and values, but reflects a variety of tasks and subcultures, since universities traditionally have been characterized by structural fragmentation or loose coupling (Cohen and March 1986; March and Olsen 1976).

According to an environmental perspective, public organizations respond to two types of environment: the technical and the institutional environment (Christensen and Lægreid 2001a; Meyer 1977). The technical environment concerns the dealing with the internal technical part of an organization. In other words, it is about productivity, efficiency, services, etc. For example when a ministry gives a university money and makes a plan for how that money should be spent, it expects the university to report the outcome and whether the money has been spent according to plan. If there is a tension in this technical relationship or increasing pressure, turbulence or crisis in the environment, this may further changes in affiliation form or internal technical and structural changes.

In the institutional environment, myths and symbols are developed and transferred to public organizations. For example, it comes to be taken for granted that certain ways of organizing public organizations are superior and good (Meyer 1977). The process of spreading such ideas, often in the form of models, prescriptions or standards, is often 
influenced by international or national 'certifying' organizations acting as reform entrepreneurs. Myths and symbols may be broad and encompassing, or else they may be much narrower and limited to certain reform elements or institutional standards (Røvik 2002).

An environmental perspective on university reform will first of all focus on whether actors in the environment, like the superior ministry, are exerting pressure on the universities to reform, or whether reform is partly self-initiated. Such a perspective will also ask whether there is more general economic, social or political pressure or crises triggering university reforms, or influencing certain parts of the reforms. A focus on the institutional environment would involve discussing whether myths, symbols and ideas from the environment play a vital part in reforms. If so, are they connected to the universities role in the knowledge economy, efficiency/financial systems, management, accountability, research, teaching, etc.

The transformational approach, containing the three perspectives outlined is also about the dynamic relationships between the contexts or constraints. There are many ways to treat this dynamic, but the one used here will take the hierarchical version of the instrumental perspective as a point of departure and ask how the leadership's design of the university reform is furthered or modified by negotiational, cultural and environmental features. More specifically we will use this approach both to support our main thesis of increased formal autonomy of universities and decreasing real autonomy, related to some developmental features of modern university reform, but also supporting a proposal for doing further research on this thesis.

\section{Development features in university governance and reforms}

Some main features of the process dynamics

The university reform processes, like the overall NPM reform processes, have comparatively often been rather top-down, with the political-administrative leadership controlling the processes, in some cases supported by parliaments, the business community or regional/local government (Christensen and Lægreid 2001b; Christensen et al. 2007; Gregory 2001; Pollitt and Bouckaert 2004). The universities and their organizations have not always been very enthusiastic about reforms, and the academic faculty and their unions even less so, while administrative staff have been more supportive (Paradeise et al. 2009a; Yamamoto 2004). The reform processes can thus be seen as products of both hierarchical steering from the superior ministries and coalition/negotiation processes. Internally the reforms have created some tension and conflicts of interests between the administrative and academic staff, and the academic staff have tended to carry the torch for academic freedom, reflecting path-dependent resistance towards the reforms (Paradeise et al. 2009b). A general cultural argument often heard from the professors about university reforms is that they are not sensitive to the traditions and special characteristics of the universities.

Changing principles and ideas

The last few decades have seen a transformation of the notion of universities-from a perception of them as a deeply specialized type of professional organization, built on specialized knowledge, academic freedom and collegiality, with an elitist character- to a perception of universities as being almost like any other type of formal organization (Ramirez 2006). This generic argument, seen by many as a myth or symbol, indicating that 
universities should not be treated in any special way, reflects the global standardization or rationalization process going on and the imitation by the public sphere of private organizational models. One central implication of such a redefinition of universities is that they should be treated in a similar way to other organizations, regardless of their different cultural traditions and formal structures and tasks. A crucial question is, of course, whether the changing notion of universities more specifically will also lead to formal and cultural changes, not to mention changing practices. For there is no guarantee that ideas and reality will be closely connected (Christensen et al. 2008).

Ramirez (2006) sees the rationalization of the university as an organization as related to more efficiency and profit orientation, and to an increasing focus on new managerial logic, all factors traditionally deemphasized in university systems, but also to three long-term broad developmental processes. First, the universities are becoming broader and more socially inclusive, reflecting the substantially increasing number of students (mass universities), but also through admitting an increasing number of women, making the elitist profile difficult to maintain in countries with a history of gender unbalance (Maasen 2008; Paradeise et al. 2009a). Secondly, the universities are becoming more socially oriented, with a shift in emphasis in the notion of knowledge to more practical and professionally useful knowledge, including an expansion of social science. Thirdly, universities are becoming more organizationally flexible towards students, but also evolved a more flexible relationship with society, by diversifying their contacts and activities with the public and private actors, for example, with respect to research, and are therefore drawing their resources from a greater range of sources (Paradeise et al. 2009b). There is also an underlying argument of isomorphism here (see DiMaggio and Powell 1983), i.e. universities are becoming gradually more similar in many ways. This can either be seen as an argument based in cultural or myth theory, namely, that there are global and national culturally oriented processes working to this end, or as a more instrumental argument, as exemplified by the Bologna process as a more specific and formal standardization process (Meyer et al. 2007).

In accordance with NPM, university reforms have been strongly oriented towards efficiency (Ferlie et al. 2008), although it has never been quite clear what is really meant by efficiency in an institution like a university, for example, with respect to research activities. The overall argument of efficiency is coupled with an argument of wider responsibility or accountability (Amaral 2008). Universities are obliged not only to be more accountable to the superior funding unit, the ministry, but also to various stake-holders in society, including private actors. Accountability is also related to increased service-orientation towards students as customers.

Concerning universities this argument is certainly related to the increasing demands being made on resources as the profile of universities changes from that of elite institutions to mass ones as well as to reduced spending per student, economic stagnation and less political willingness to give priority to education over other policy areas (Paradeise et al. $2009 \mathrm{~b}$ ). Another important factor is the changing notion of the societal function of higher education, related to the knowledge-based economy, economic growth and increased attention to the needs of the labour market, with a demand on university staff to change their cultural norms and values accordingly (Goodin 2003). A narrow and introvert profile has been under pressure and a new and open one emerging.

The combined efficiency and accountability argument is also of a symbolic kind. After all, one can hardly argue against the view that universities, like any other public organization, must use scarce money in an efficient and responsible way. During the university reforms, it has not been easy to argue that university activities are primarily about teaching 
and research, and that by their nature neither of these activities lends itself well to a primary focus on efficiency. The big question is, of course, how this general goal of efficiency may be achieved. The answer from the NPM camp to the universities, as indeed to other types of public organizations, is that they should become more structurally autonomous, develop modern financial systems and be more professional in their management orientation, i.e. they should make greater use of modern management principles (Paradeise et al. 2009a).

\section{Specific structural reform measures ${ }^{2}$}

The university reforms might be seen as a repertoire of NPM-inspired reform measures that has been used to different degrees in different countries, i.e. combining convergence and divergence (Paradeise et al. 2009b: 219-220). First and very important, in many cases universities' formal structural affiliation with the central public authorities has been changed. Before modern university reforms started during the last decades, universities were often administrative bodies, either with a special status or seen as an extension of the ministries, i.e. they have formally had a rather close and integrated connection with the ministries of education and research. ${ }^{3}$ Analytically this can be characterized as scoring low on vertical inter-organizational specialization (Christensen et al. 2008). The modern university reforms have changed their formal affiliation in a much more specialized direction, increasing the formal distance between the ministries and the universities. This increased distance has taken different forms, making the universities like either agencies, public enterprises/corporate organizations (SOE) or foundations, but the basic point is that the formal autonomy of the universities has increased in one way or another related to the main form of affiliation (Paradeise et al. 2009a).

Quite often we also find hybrid forms in university reforms, where elements are taken from different affiliation types - as in Japan, where the reform combines an agency and a more corporate type of affiliation (Yamamoto 2004), or Norway, where a more traditional bureaucratic form of affiliation is combined with elements from the corporate form when it comes to appointing external representatives (Bleiklie 2009). Another way to look at hybridity is to stress that modern university reforms, as with public sector reforms more generally, give with one hand and take back with the other, i.e. they combine deregulation and reregulation (Christensen and Lægreid 2006). The overall increase in autonomy, and increasing financial and management autonomy, is counteracted by more steering and control instruments like more standardized rules for different activities, increased use of scrutiny and control systems, more use of incentive systems, more reporting to superior authorities, etc., which will be more specified below. All this is making it more of an open question whether increased formal autonomy is that evident and unambiguous, not to mention that this is giving more actual or real autonomy.

In the rhetoric around university reforms their increased autonomy is stressed, while the control side is played down (Amaral 2008). The reality in most countries seem to be that the reforms have tilted the balance on the central control-autonomy dimension, somewhat

\footnotetext{
2 The empirical basis of the article is partly own studies of Norwegian university reform in the 1990s, partly a recent comparative study commissioned by the Center for National University Finance and Management in Tokyo (Christensen 2009), but also a review of the relevant comparative literature.

3 Taking a longer historical perspective, universities around the world have been established by a wide variety of institutions, like public organizations, church societies and non-profit interest groups, and have also had very different forms of affiliation to public authorities.
} 
in the formal autonomy direction. But as indicated, there is definitely a dynamic and potentially tension-filled relationship between control and autonomy, making it rather difficult to judge the actual autonomy of universities following modern reforms.

Overall, modern university reforms seem to give universities more formal freedom with regard to some major functions, even though actual freedom, as mentioned, will vary (Paradeise et al. 2009b). Modernized universities have considerably more formal say in deciding on their budgets, and they normally now get their money in a lump sum. This generally gives them more discretion than before, when money from the government was allocated on a line-item basis and much more ear-marked. Second, universities have also increased their control over their real estate and over the property they own and administrate. Third, they have acquired greater freedom to decide on their own internal decisionmaking structures and management.

At the same time, following the reforms the universities are now much more under scrutiny than before (Paradeise et al. 2009b). They are held more accountable, which involves reporting more to the central authorities, often the ministries. Strategic steering has in many cases been introduced, which involves formal goals, plans, letters of intent from the ministries, performance management, more reporting from the universities of results, etc. As a result the so-called steering-dialogue between ministries and universities has become much more formalized and intense than before the reforms. In addition, the basic dependence of the universities on the overall laws/rules regulating them, and the power of the central purse has not diminished after the reform. There is also a stronger emphasis on auditing and evaluation, making new external actors significant for university steering.

The balance and tension between increasing autonomy on the one hand, and continued control of the universities and external dependence on the other, is rather evident in the simple fact that in most countries the university reforms have made universities more dependent on sources other than the basic public funding. In other words, a process of diversification has taken place regarding funding (Paradeise et al. 2009b). One logic behind this is a changing notion of the universities as totally reliant on public funding, reflecting increasing scarcity of public money for higher education, or less political willingness to allocate such funding, but also the attitude that universities should be more independent in this regard. Another line of reasoning is that universities should be able to be more efficient after the reforms and should therefore need less money from the government. In some countries, like Japan, the government has put additional pressure on universities to be efficient by cutting their basic funding (Yamamoto 2009).

In many countries, such as in Europe, university funding is often public. Even in countries with a large share of private universities, the government is an important source of funding. The funding of public universities has not changed dramatically as a result of the reforms, and probably less so in Europe than in other parts of the world. There is, however, now more pressure (and incentives) to obtain funding from sources other than the public purse. This generally makes universities more vulnerable and more dependent on the environment. Universities have always managed to obtain research money from sectoral ministries and agencies, but there now seems to be much more competition for these resources. The same goes for resources channeled through research councils, which probably favours universities that are strong on research, as shown in Japan (Mizuta 2008). Competition for private research money has also increased. Not all public universities have tuition fees, but the reforms have put pressure on the ones that do to raise their fees, albeit within government constraints. In countries without tuition fees there has been more public debate since the reforms about introducing fees. 


\section{Analyzing university reform}

We will now discuss whether our thesis presented earlier could be supported by an analysis based on the transformation approach. The first part of it is that the 'old' university system was characterized by low formal autonomy but high actual autonomy. Evidently the public universities, for example in Europe, have traditionally been defined formally as either part of the public administration or as administrative bodies with a special status, i.e. meaning overall having rather low formal autonomy (Paradeise et al. 2009a). Why was this status in reality representing a high actual autonomy? One reason is that in the pre-NPM age, there were very few formal control instruments developed related to standards, incentives and reporting, meaning that the universities were more 'left alone', in spite of their formal status. Universities were also seen as having a rather narrow societal role leaving them with low environmental pressure. Second, and adding to this, the culture in society and among the political-administrative leaders was definitely that the universities should have a lot of autonomy. Third, the main group inside the universities, the professors, managed to sell the myth that academic and institution freedom were major preconditions for good quality universities, and they had little competition from other groups, like university administrators in doing that, because they more defined themselves as 'helpers' for the academic staff. In the 'pre-management' period university administration was small and the (organizational) autonomy of the university was very much seen as similar to the professional autonomy of academics.

The second part of the thesis is that modern university reforms develop universities with higher formal autonomy than the old ones, but lower autonomy in reality. How could that be supported based on the transformation approach? The structural-instrumental perspective can provide insight into the reorganization reform measures and their effects. A basic feature is changing the form of affiliation between the superior ministerial authorities and the universities. Here the tendency has been towards more structural devolution or vertical inter-organizational specialization (Egeberg 2003), although there is some variation among countries and between universities in this respect, with the corporate form and the foundation form at one end of the spectrum.

Studies of structural changes of this kind in public organizations more in general show quite clearly that they produce less central control and more institutional and professional autonomy (Christensen and Lægreid 2001b; Pollitt and Bouckaert 2004). They have 'given away' formal decision-making authority and have less information about what is going on in these bodies, but still often get the blame when things go wrong (see Brunsson 1989). To the structural argument can be added the cultural and environmental ones, which say that the pressure for political executives not to interfere after devolutionary change has been strong. This reflects the rather anti-political flavour of NPM, which says something like 'it is better for politicians to stay away from many decisions in public organizations, especially the more complicated ones involving professional expertise' (Christensen and Lægreid 2001a).

The picture outlined so far seems to show without doubt more formal autonomy for the new universities than the old ones, and also indicate, based on more general studies, more autonomy in reality. The latter part is, however, very much debatable. Only focusing on affiliation form is a rather narrow look at the formal structure, so we have to take into account that many general studies have shown a dynamic of deregulation/devolution on the one hand for subordinate public institutions, but a reregulation on the other hand, i.e. that central authorities both let go and control more at the same time, in more hybrid formal structures (Christensen and Lægreid 2007). 
If we transfer these more general findings to the university sector, it's evident that increased formal autonomy for the universities is coupled with more formal demands from the superior ministry, i.e. there are more hierarchical strings attached. University laws increasing define standards for the different functions of the universities, making the autonomy more limited. More formal and demanding systems of scrutiny, comtrol and auditing have been developed, likewise performance management and reporting systems, not to mention economic incentive systems where money is following the students or attached to research activities. All this is very much limiting in reality the increased formal autonomy universities have got. So the increased multi-dimensional formal autonomy is 'counter-acted' by multiple instruments of control, i.e. it's a dynamic of deregulation and reregulation. The generic definition and rationalization of the universities is focusing more on the managerial discretion and control and not the academic-professional autonomy and influence (Ramirez 2006),

Could negotiation features participate in supporting the conclusion that the real autonomy is weakened? One major argument would be that the actor structure concerning decisions in universities has changed quite a lot, from one dominated by professors to one that is much more heterogeneous concerning actors and influence. One increasingly important group is university management on different level, a group that was of very little significance in the old universities. One major function or rationale behind their development is that professional university management should participate in improving university steering and created better opportunities for different activities. This implies very much to inform the university societies about the new and implement the emerging systems of control, performance, incentives, reporting, etc., which imply a more central role for them. They also have a central function in reporting to the central authorities about results related to the different activities in universities. The preconditions for university management to have an alliance with the superior ministries is definitely there, something that is shown in many conflicts with the academic staff. This argument do not, of course preclude that university management may some times resist superior control and side with professors, but their structural role is rather asymmetric related to the ministries.

Another negotiation feature is the increasing representation of external members of university boards and other collegial bodies. Egeberg (2003) point to the fact that boards connected to public agencies do not have a distinct profile, because they can be both seen as steering instruments for superior authorities, as instruments for the agencies towards the ministries, or more for a of discussion without any clear function. External representatives at university boards seem to have a tendency either to have a profile as representing the society at large, as instruments for the owner (ministry) or as independent professional representatives (for example business people). In all these capacities they seem to enact some kind of controlling role that may be limiting the formal autonomy of the universities.

The formal increase in structural autonomy and the modifications brought by different strings attached from the ministries, could also be influenced by cultural factors. One of these is that the formal reform measures may have trouble being implemented as intended, either because the ministry is reluctant to 'relinquish authority' or because path-dependence and traditions in the universities counteract or slow down the reforms, i.e. they are skeptical about the alleged effects of increased formal autonomy. This argument is definitely valid for the group of professors often trying to counter-act, modify or ignore reforms, but universities as such, including their management, may resist reforms, as exemplified with the Japanese university reform in 2004 (Christensen 2009).

Another factor is whether the 'steering dialogue' between the ministries and universities will be strictly formal or whether there will be informal continuous dialogue, where the 
ministries give informal signals and universities both adapt and provide input of their own. This mechanism is rather common in new formal performance-management systems that seem to be too rigid (Bouckaert and Halligan 2007). For some, structural devolution means 'steering once a year', while in practice it often takes the form of a continuous and dynamic process of dialogue and exchange. And in such a dialogue the ministry will often have the upper hand, because the ministry-university relationship is so asymmetric.

If we look at the environmental perspective, it could also participate in explaining why increased formal autonomy may lead to limited actual autonomy. The technical environment can explain that the superior authorities have increased their efforts to put pressure on the universities. One central part of this to place the universities in a knowledge economy context, trying to make them more instrumental for society and more efficient. Another, the increasing use of financial incentives, either directly through, as mentioned, the money following the students or research, but also through pressuring the universities to look elsewhere for research money. This makes the universities more vulnerable both towards alternative public sources and more private research money (Enders et al. 2008). There is also an increasing pressure towards the universities related to another main group of stakeholders, the students, which is demanding more resources.

The institutional environment has also been rather unfavorable towards the universities the last decades, putting a symbolic pressure on them. The symbols of the knowledge economy and efficiency, not to mention accountability, have managed to portrait them as closed and inefficient.

Summing up, our main argument for concluding that the 'new' universities have more formal autonomy, but less real autonomy than the 'old' ones, is connected partly to development of superior ministries having many formal strings attached through the emerging scrutiny/control, incentive and performance management systems. But modifying negotiational factors, reflecting changing internal patterns of influence, cultural factors developing more of a management culture, and increase environmental pressure is also part of the equation. One indication supporting the thesis is also that the core group of actors at the universities has been very little interested, often resisting, the alleged new autonomy for the universities, indicating that they were satisfied with the actual autonomy in the good old days and more careful about the real autonomy under the new university regime (Amaral 2008). As the generic definition of universities comes to prevail, they will see themselves as under double attack from increased formalization and management-orientation, with respect to both the ministry and to the growing internal management component. They will feel that their teaching and research is more subject to management in the form of incentive and reporting systems. As such they will feel that their professional autonomy is decreasing.

The crucial question then is why one can argue that the effects of the university reforms will be different from the main effects of NPM-type reforms, as shown in several studies (Christensen and Lægreid 2001b; Pollitt and Bouckaert 2004). One historical reason for this, of course, is that universities have been different from ordinary public organizations, like ministries and agencies, in several ways. They have had a rather limited internal administration, a looser coupling between the administration and the core specialized academic activities, a university's core activities (particularly research) are more deeply specialized, and the academic staff have much more professional autonomy than ordinary civil servants. In other words, both their formal organization and their culture are different. The NPM-related university reforms, developed in other types of organizations, will therefore have other types of effects in universities. 
A supportive argument for our main thesis, takes as a point of departure the post-NPM reforms that emerged in the late 1990s, often in trail-blazing NPM countries, as a reaction to the effects of the NPM reforms, but for other reasons as well (Christensen et al. 2007; Christensen and Lægreid 2007; Gregory 2003; Halligan 2006). Post-NPM reforms have focused much more on central control and coordination and have both a vertical and a horizontal dimension. Our argument will be that these reform elements will modify the effects of the NPM-related university reforms. One obvious possibility is that the control and scrutiny measures already installed through NPM will be used more extensively, with a greater emphasis on the vertical integrative aspect. This can probably be furthered by the financial recession also, where the universities are given more money to absorb some of the consequences of increased unemployment, and there will be an increased need to control these resources. But the recession could also lead to plain cuts in the resources to the universities, also a control measure.

\section{How to study the paradox of university autonomy?}

We will indicate different possible ways to research our thesis of increased formal autonomy and decreasing actual autonomy in universities, as part of a continued research agenda in this area. As a point of departure, one has to do a longitudinal comparison between old and new university systems, for example in 1980 and 2010. To differentiate such a design, one could either compare university systems in different countries, or universities inside one country, which could have the function of either see whether there are similar development in university systems between countries or a differentiated development that could give a better insight into the effects of different structural designs. Comparisons inside one country could focus whether standardized university reforms are having differentiated effects on different types of universities, like studies of Japanese university reform seem to indicate (Mizuta 2008; Yamamoto 2009).

An empirical start based on the instrumental-structural perspective would be to focus on a broad variety of formal structures over time, reflected in laws, rules, procedures, organigrams, etc., and see how they are changing over type, to document the emerging formal autonomy. Adding to this would be to describe when and how control, management, financial and reporting systems for universities are established and emerging over time. Combining these two sources would indicate the emerging formal autonomy and the new formal strings attached from superior authorities. The increasing formalization of many functions and activities in universities could also be documented in this way.

Concerning changing cultures in the universities, one could focus on the development of common cultures or sub-cultures, reflected in university history research, in media debates or in internal debates at the universities. Do we find indications of changing cultures over time related to control and efficiency? Are increasing tensions and conflicts concerning culture between different groups, including management and academic staff, reflected in this type of data?

An environmental perspective could first lead to efforts of documenting the alleged increasing pressure on the universities, related to the knowledge economy, efficiency, accountability, etc., whether found in public documents, parliamentary debates, media coverage, internal debates at the universities, etc. The same type of material could also be used to emphasize the changing symbols of university reform.

One crucial question related to research our main thesis is how to get good indicators on real or actual autonomy. Adding to the sources we already have indicated, would be to ask 
a variety of central actors in university reform and university system about their experiences and opinions. This could either be done in broad surveys or in more focused case studies with more in-depth interviews.

\section{Conclusion}

The focus in this article has been to discuss a main thesis related to university reform, a thesis that seems to be a paradox, namely that modern university reform has changed university system from having low formal autonomy and high real autonomy, to a situation of high formal autonomy and low actual autonomy. Our discussion of this thesis is based on two pillars, first a transformative approach contain instrumental, cultural and environmental perspectives, and second an outline of main development trends in university reform.

Our main argument supporting this thesis is the following: University reform very much reflect more broadly NPM-oriented reforms, both related to the generic ideas that all (public) organizations are similarly or should be treated similar, but also concerning more specific structural and cultural reform measures. Formal autonomy is multi-dimensional and many strings are attached seen from the ministries behind the reforms, so deregulation is paired with reregulation through control and reporting system, standardizing measures of different kinds, incentives systems or cut-back management, something that is limiting their actual autonomy. Compared to the historical high actual autonomy, something different from ordinary agencies, there is a 'relative deprivation' going on. Changing power relations inside the universities, with the university management becoming relatively stronger is supporting this development, because it's very much legitimating their emergence, professionalization and growth, while the traditional emphasis on the academicprofessional autonomy is weakened.

Many universities also search more for additional or alternative financial resources, increasing their dependence of external stake-holders, undermining the traditional autonomy related to a secured public financing and the superior ministry 'protecting' the universities from other stakeholders. Changing university cultures, with more management elements, weaker academic-professional elements and stronger environmental pressure is also underlying the decreasing real autonomy of universities. Adding to this is the emerging postNPM elements of more control and centralization, which may be stronger with a developing financial recession.

Open Access This article is distributed under the terms of the Creative Commons Attribution Noncommercial License which permits any noncommercial use, distribution, and reproduction in any medium, provided the original author(s) and source are credited.

\section{References}

Amaral, A. (2008). Transforming higher education. In A. Amaral, I. Bleiklie, \& C. Musselin (Eds.), From governance to identity. A Festschrift for Mary Henkel. Berlin: Springer.

Bleiklie, I. (2009). Norway: From tortoise to eager beaver? In C. Paradeise, E. Reale, G. Goastellec, I. Bleiklie, \& E. Ferlie (Eds.), A comparative approach to higher education reforms in Western Europe Countries. University Governance. Western European Comparative Perspectives. Berlin: Springer.

Boin, A., \& Christensen, T. (2008). The development of public institutions: Reconsidering the role of leadership. Administration \& Society, 40(3), 271-297. 
Boston, J., Martin, J., Pallot, J., \& Walsh, P. (1996). Public management: The New Zealand model. Auckland: Oxford University Press.

Bouckaert, G., \& Halligan, J. (2007). Managing performance: International comparisons. London: Routledge.

Brunsson, N. (1989). The organization of hypocrisy. Talk, decisions and actions in organizations. Chichester: Wiley.

Christensen, T. (2009). University governance reforms-putting the Japanese experience into perspective. Tokyo: A Report to the Center for National University Fianance and Management.

Christensen, T., \& Lægreid, P. (2001a). A transformative perspective on administrative reforms. In T. Christensen \& P. Lægreid (Eds.), New public management. The transformation of ideas and practice. Aldershot: Ashgate.

Christensen, T., \& Lægreid, P. (2001b). New public management-Undermining political control? In T. Christensen \& P. Lægreid (Eds.), New public management. The transformation of ideas and practice. Aldershot: Ashgate.

Christensen, T., \& Lægreid, P. (Eds.) (2006). Autonomy and regulation. Coping with agencies in the modern state. London: Edward Elgar.

Christensen, T., \& Lægreid, P. (2007). The whole-of-government approach to public sector reform. PAR: Public Administration Review, 67, 1059-1066.

Christensen, T., Lægreid, P., Roness, P. G., \& Røvik, K. A. (2008). Organization theory and the public sector. London: Routledge.

Christensen, T., Lie, A., \& Lægreid, P. (2007). Still fragmented or reassertion of the centre? In T. Christensen \& P. Lægreid (Eds.), Transcending new public management. Aldershot: Ashgate.

Cohen, M. D., \& March, J. G. (1986). Leadership and ambiguity. The American College President (2nd ed.). Boston: Harvard University Press.

Cyert, R. M., \& March J. G. (1963). A behavioral theory of the firm. Englewood Cliffs, N.J.: Prentice-Hall.

Dahl, R. A., \& Lindblom, C. E. (1953). Politics, economics, and welfare. New York: Harper \& Row.

DiMaggio, P., \& Powell, W. W. (1983). The iron cage revisited: Institutional isomorphism and collective rationality in organizational fields. American Sociological Review, 4, 147-160.

Egeberg, M. (2003). How bureaucratic structure matters: An organizational perspective. In B. G. Peters \& J. Pierre (Eds.), Handbook of public administration. London: Sage.

Enders, J., De Boer, H., \& Leisyte, L. (2008). On striking the right note: Shifts in governance and the organizational transformation of universities. In A. Amral, I. Bleiklie, \& C. Musselin (Eds.), From governance to identity. A Festschrift for Mary Henkel. Berlin: Springer.

Ferlie, E., Musselin, C., \& Andresani, G. (2008). The steering of higher education systems: A public management perspective. Higher Education, 56, 325-348.

Goodin, B. (2003). The knowledge-based economy: Conceptual framework or buzzword? Project on the History and Sociology of S\&T statistics. Working paper no. 23.

Gregory, R. (2001). Transforming governmental culture: A sceptical view of new public management. In T. Christensen \& P. Lægreid (Eds.), New public management. The transformation of Ideas and practice. Aldershot: Ashgate.

Gregory, R. (2003). All the King's Horses and all the King's Men: Putting New Zealand's public sector back together again. International Public Management Review, 4(2), 41-58.

Gulick, L. (1937). Notes on the theory on organizations. With special reference to government. In L. Gulick \& L. Urwin (Eds.), Papers on the science of administration. New York: A. M. Kelley.

Halligan, J. (2006). The reassertion of the centre in a first generation NPM system. In T. Christensen \& P. Lægreid (Eds.), Autonomy and regulation. Coping with agencies in the modern state. London: Edward Elgar.

Halligan, J. (2007). Reform design and performance in Australia and New Zealand. In T. Christensen \& P. Lægreid (Eds.), Transcending new public management. Aldershot: Ashgate.

Krasner, S. D. (1988). Sovereignty. An institutional perspective. Comparative Political Studies, 21(1), 66-94.

Maasen, P. (2008). The modernization of european higher education: National policy dynamics. In A. Amral, I. Bleiklie, \& C. Musselin (Eds.), From governance to identity. A Festschrift for Mary Henkel. Berlin: Springer.

March, J. G., \& Olsen, J. P. (1976). Ambiguity and choice in organizations. Bergen: Universitetsforlaget.

March, J. G., \& Olsen, J. P. (1983). Organizing political life. What administrative reorganization tells us about government. American Political Science Review, 77, 281-297.

Meyer, J. W., \& B. Rowan (1977). Institutionalized organizations: Formal structure as myth and ceremony. American Journal of Sociology, 83, 340-363. 
Meyer, J. W., Ramirez, F. O., Frank, D. J., \& Schofer, E. (2007). Higher education as an institution. In P. Gumport (Ed.), Sociology of higher education (pp. 187-221). Baltimore: The John Hopkins University Press.

Mizuta, K., \& Yanaguira, T. (2008). Policy analysis on the effectiveness of the national university corporation act: What has changed since 2004? Scholarly Paper for Session-F. ASHE Annual Conference at Jacksonville in Florida, 11 July, 2008.

Mosher, F. (Ed.) (1967). Governmental reorganizations. Indianapolis: Bobbs-Merrill Company.

Paradeise, C., Bleiklie, I., Enders, J., Goastellec, G., Michelsen, S., Reale, E., et al. (2009a). Reform policies and change processes in Europe. In J. Huisman (Ed.), International perspectives on the governance of higher education. Alternative frameworks for coordination. New York: Routledge.

Paradeise, C., Reale, E., \& Goastellec, G. (2009b). A comparative approach to higher education reforms in Western Europe Countries. In C. Paradeise, E. Reale, I. Bleiklie, \& E. Ferlie (Eds.), University governance. Western European comparative perspectives. Berlin: Springer.

Paradeise, C., Reale, E., Goastellec, G., \& Bleiklie, I. (2009c). Universities steering between stories and history. In C. Paradeise, E. Reale, I. Bleiklie, \& E. Ferlie (Eds.), University governance. Western European comparative perspectives. Berlin: Springer.

Pollitt, C., \& Bouckaert, G. (2004). Public management reform: A comparative analysis (2nd ed.). Oxford: Oxford University Press.

Ramirez, F. O. (2006). The rationalization of universities. In M.-L. Djelic \& K. Sahlin-Andersson (Eds.), Transnational governance: Institutional dynamics of regulation. Cambridge: Cambridge University Press.

Richards, D., \& Smith, M. (2006). The tensions of political control and administrative autonomy: from NPM to a reconstituted Westminster model. In T. Christensen \& P. Lægreid (Eds.), Autonomy and regulation. Coping with agencies in the modern state. London: Edward Elgar.

Røvik, K. A. (2002). The secrets of the Winners: Management ideas that flow. In K. Sahlin-Andersson \& L. Engwall (Eds.), The expansion of management knowledge-carriers, flows and sources. Stanford, CA: Stanford University Press.

Selznick, P. (1957). Leadership in administration. New York: Harper \& Row.

Simon, H. A. (1957). Administrative behaviour. New York: Macmillan.

Wright, V. (1994). Reshaping the state. The implications for public administration. West European Politics, $17,102-137$.

Yamamoto, K. (2004). Corporatization of national universities in Japan: Revolution for governance or rhetoric for downsizing? Financial Accountability \& Management, 20(2, May), 153-181.

Yamamoto, K. (2009). Programme-oriented budgeting in public universities: The case of a national university in Japan. Paper for the EGPA Conference, Sept. 2-5, Malta. 